\title{
Low-temperature fabrication of macroporous scaffolds through foaming and hydration of tricalcium silicate paste and their bioactivity
}

\author{
Zhiguang Huan $\cdot$ Jiang Chang $\cdot$ Jie Zhou
}

Received: 30 July 2009/Accepted: 9 November 2009/Published online: 18 November 2009

(C) Springer Science+Business Media, LLC 2009

\begin{abstract}
A low-temperature fabrication method for highly porous bioactive scaffolds was developed. The twostep method involved the foaming of tricalcium silicate cement paste and hydration to form calcium silicate hydrate and calcium hydroxide. Scaffolds with a combination of interconnected macro- and micro-sized pores were fabricated by making use of the decomposition of a hydrogen peroxide $\left(\mathrm{H}_{2} \mathrm{O}_{2}\right)$ solution that acted as a foaming agent and through the hydration of tricalcium silicate cement. It was found possible to control the porosity and pore sizes by adjusting the concentration of the $\mathrm{H}_{2} \mathrm{O}_{2}$ solution. The in vitro bioactivity of the highly porous scaffolds was investigated by immersion in simulated body fluid (SBF) for 7 days. Hydroxyapatite (HAp) was formed on the surface of the scaffolds. Their bioactivity could be expected to be as good as that of tricalcium silicate cement, making the material competent for the bone tissue engineering application.
\end{abstract}

\section{Introduction}

One of the effective approaches in solving the problem of bone regeneration and repair is bone tissue engineering. To

\footnotetext{
Z. Huan · J. Chang $(\bowtie)$

Biomaterials and Tissue Engineering Research Center, Shanghai Institute of Ceramics, Chinese Academy of Sciences, 1295 Dingxi Road, Shanghai 200050,

People's Republic of China

e-mail: jchang@mail.sic.ac.cn

Z. Huan · J. Zhou

Department of Materials Science and Engineering,

Delft University of Technology, Mekelweg 2,

2628 CD Delft, The Netherlands
}

guide in vitro or in vivo tissue regeneration, it is prerequisite to have appropriate scaffold materials with characteristics that satisfy all the requirements for bone tissue engineering, i.e., having the ability to deliver cells, interconnected macroposity, osteoconductivity, controlled degradation, sufficient mechanical properties, and formability [1]. Silicate-containing bioactive materials such as calcium silicate $\left(\mathrm{CaSiO}_{3}\right)$ and bioglass are advantageous over other candidate scaffold materials for bone tissue engineering with respect to osteoconductivity [2], bioactivity [3-5], the ability to deliver cells [6], and controllable biodegradability [7].

In the past, attempts have been made to fabricate bioactive scaffolds in various configurations and with different ranges of pore sizes by means of the techniques for the manufacturing of porous ceramics, such as dry-powder processing with the addition of porogen [8-10], sol-gel and gel-casting [11], and the replication technique [12-14] (also called the polymer-sponge method). All these methods involve high-temperature sintering to remove the porogen or replication matrix and to achieve extensive densification in order to avoid the detachment of particles from the scaffold material. It has been recognized that such a high-temperature processing step may cause undesirable crystallization or phase transformation of a constituent component in the scaffold and thus turns a bioactive and biodegradable silicate into an inert material $[15,16]$. Moreover, the need to expose the material to a high sintering temperature excludes the possibility of introducing proteins and many other kinds of drugs into the material, for example, antibiotics, anti-inflammatory or anticancer drugs. It is therefore of great interest to take an alternative processing route and fabricate porous bioactive scaffolds at low temperatures. 
The present research was aimed to develop the method of preparing macroporous silicate-containing bioactive scaffolds from tricalcium silicate $\left(\mathrm{Ca}_{3} \mathrm{SiO}_{5}\right.$ or $\left.\mathrm{C}_{3} \mathrm{~S}\right)$ cement at low temperatures. $\mathrm{C}_{3} \mathrm{~S}$ is known as an important component in Portland cement. Once mixed with water, $\mathrm{C}_{3} \mathrm{~S}$ reacts with water to form calcium silicate hydrate $(\mathrm{C}-\mathrm{S}-\mathrm{H})$ as Eq. 1 [17]

$$
\begin{gathered}
\mathrm{Ca}_{3} \mathrm{SiO}_{5}+(3+y-x) \mathrm{H}_{2} \mathrm{O} \rightarrow(\mathrm{CaO})_{x}\left(\mathrm{SiO}_{2}\right)\left(\mathrm{H}_{2} \mathrm{O}\right)_{y} \\
{[\mathrm{C}-\mathrm{S}-\mathrm{H}]+(3-x) \mathrm{Ca}(\mathrm{OH})_{2}}
\end{gathered}
$$

where $x$ and $y$ can change during the course of the reaction. At stage of the reaction, a hydrated orthosilicate (monomer $\mathrm{C}-\mathrm{S}-\mathrm{H}$ ) forms in a cement paste, followed by the formation of dimeric silicates. Then, dimers polymerize to form pentamers, octomers, etc., which can be modeled as a progressive insertion of bringing tetrahedra into the gaps between dimers to form the "dreierketten" structure of tobermorite [18, 19]. The agglomeration and subsequent solidification of $\mathrm{C}-\mathrm{S}-\mathrm{H}$ networks contribute to the selfsetting properties of the hydrated $\mathrm{C}_{3} \mathrm{~S}$ paste and to its enhanced mechanical strength [18]. From the biological and clinical point of view, tricalcium silicate possesses a number of important characteristics that are also noted for other silicate-containing bioactive materials. Being biocompatible, tricalcium silicate cement can induce bone-like apatite formation in simulated body fluid (SBF) and have the potential to stimulate cell proliferation [20, 21]. Moreover, the hydration product of tricalcium silicate cement is degradable in SBF [21]. All those important features suggest that tricalcium silicate is a good candidate material. It was therefore chosen in the present research for the low-temperature fabrication of bioactive scaffolds for tissue engineering by taking advantage of its self-setting properties.

In the present research, a low-temperature fabrication method for macroporous bioactive $\mathrm{C}_{3} \mathrm{~S}$ scaffolds was developed on the basis of the prior experience gained in working with tricalcium silicate cement [21] and the lowtemperature fabrication method using hydrogen peroxide $\left(\mathrm{H}_{2} \mathrm{O}_{2}\right)$ as a foaming agent that was developed by Ginebra et al. [22]. It was expected that porous scaffolds with sufficient mechanical strength could be fabricated through the foaming and setting of $\mathrm{C}_{3} \mathrm{~S}$ paste without the need of taking the sintering step. To satisfy this expectation, the compressive strength and porosity of the prepared scaffolds were determined. In addition, the in vitro bioactivity of the scaffolds was evaluated by soaking the scaffolds in SBF and the possibility of surface modification by the formation of a bone-like apatite layer was studied.

\section{Materials and methods}

Materials, scaffold preparation, and microstructure characterization

The starting material was a tricalcium silicate $\left(\mathrm{C}_{3} \mathrm{~S}\right)$ powder prepared by using the sol-gel method as described elsewhere [20]. The powder was ground and sieved through a sieve with a mesh size of $50 \mu \mathrm{m}$. To prepare the scaffolds, the $\mathrm{C}_{3} \mathrm{~S}$ powder was mixed with aqueous solutions of hydrogen peroxide $\left(\mathrm{H}_{2} \mathrm{O}_{2}\right.$, Sinopham Chemical Reagent Co., Ltd) at different concentrations (0 vol\% being deionized water, 10, 20, 30, and $40 \mathrm{vol} \%$ ). The $\mathrm{H}_{2} \mathrm{O}_{2}$ solution served as a foaming agent and the liquid to powder ratio was $0.8 \mathrm{~mL} / \mathrm{g}$. After mixing, the paste was poured into a polytetrafluoroethylene mold with a diameter of $6 \mathrm{~mm}$ and a height of $12 \mathrm{~mm}$ and held at $60{ }^{\circ} \mathrm{C}$ for $2 \mathrm{~h}$. The decomposition of the $\mathrm{H}_{2} \mathrm{O}_{2}$ solution at this temperature resulted in the foaming of the paste. The samples with 0 , 10, 20, 30, and $40 \% \mathrm{H}_{2} \mathrm{O}_{2}$ were designated as Cement-D, Scaffold-10H, Scaffold-20H, Scaffold-30H, and Scaffold$40 \mathrm{H}$, respectively.

With the scaffolds foamed, they were placed in a water bath maintained at $37{ }^{\circ} \mathrm{C}$ and in an atmosphere of $100 \%$ relative humidity (RH), and kept for 7 days (aging), followed by material characterization. As Scaffold- $40 \mathrm{H}$ was too difficult to handle due to the low mechanical strength, only the samples prepared with $0,10,20$, and $30 \% \mathrm{H}_{2} \mathrm{O}_{2}$ solutions were subjected to material characterization. The formed phases were identified using an X-ray diffractometer (XRD; Geigerflex, Rigaku Co., Japan) with monochromated $\mathrm{CuK}_{\alpha}$ radiation and the $2 \theta$ range was from 10 to $80^{\circ}$ at a scanning speed of $10 \% \mathrm{~min}$. The morphology of the porous scaffolds was observed using an optical microscope (Leica 020-520-007 DM/LP). The microstructure on the cross-section of samples was examined by scanning electron microscopy (SEM; JSM-6700F, JEOL, Tokyo, Japan).

\section{Porosity determination}

The method to determine porosity was developed from a reported convenient way [23] according to Archimedes principle and a moderate modification has been made based on a standard procedure (ASTM C 20-00) [24]. After aging in a water bath at the $37{ }^{\circ} \mathrm{C}$ and $100 \%$ RH for 7 days, the scaffold was dried at room temperature and its weight was recorded as $m_{0}$ :

$m_{0}=d_{\mathrm{a}} \times V_{\mathrm{a}}$

where $V_{\mathrm{a}}$ and $d_{\mathrm{a}}$ are the apparent volume and apparent density of the dried scaffold, respectively. Afterwards, the scaffold was immersed in ethanol for $24 \mathrm{~h}$ for the complete 
intrusion of the liquid medium. The wet sample was immediately weighed and its weight noted as $m_{l}$ :

$m_{1}=d_{\mathrm{a}} \times V_{\mathrm{a}}+d_{1} \times V_{\mathrm{p}}$

where $d_{1}$ is the density of the liquid medium, i.e., the density of ethanol in this case, and $V_{\mathrm{p}}$ the volume of the pores inside the sample. With $m_{1}$ registered, the specimen was immediately transferred to a beaker containing $50 \mathrm{~mL}$ ethanol and the suspending weight of the sample soaking in ethanol was recorded as $m_{2}$, which is taken as the weight of the scaffold soaking in ethanol in case that the pores within the material were completely filled by ethanol [24]:

$m_{2}=d_{\mathrm{a}} \times V_{\mathrm{a}}+d_{1} \times V_{\mathrm{p}}-d_{1} \times\left(V_{\mathrm{a}}+V_{\mathrm{p}}\right)$

The total porosity $P_{\text {total }}$ should be:

$P_{\text {total }}=V_{\mathrm{p}} /\left(V_{\mathrm{a}}+V_{\mathrm{p}}\right)$

With this method, the total porosity $P_{\text {total }}$ can be calculated using Eq. 6 [24]:

$P_{\text {total }}=\left[\left(m_{1}-m_{0}\right) /\left(m_{1}-m_{2}\right)\right] \times 100 \%$

It should be noted that the tricalcium silicate paste as the matrix of the scaffold is inherently microporous [21]. Therefore, $P_{\text {total }}$ should be the summation of the inherent microporosity $P_{\text {micro }}$ of the reacted tricalcium silicate paste and the macroposity $P_{\text {macro }}$ created by the foaming agent. To determine $P_{\text {micro }}$, a porosity test of the 7-day-set tricalcium silicate paste aged with deionized water (Cement-D) was performed, following the steps as described above. Then, the macroporosity created by the foaming agent $P_{\text {macro }}$ could be determined by using Eq. 7:

$P_{\text {macro }}=P_{\text {total }}-P_{\text {micro }}$

Six replicated tests were performed to determine the porosity of each scaffold and the results were expressed in the form of mean \pm standard deviation (SD).

\section{Mechanical testing}

After aging in a water bath at $37{ }^{\circ} \mathrm{C}$ and $100 \% \mathrm{RH}$ for 7 days, the scaffolds were dried at room temperature and then carefully cut into specimens with a diameter of $6 \mathrm{~mm}$ and a height of $8 \mathrm{~mm}$ for mechanical testing. The surface of the specimen was slightly polished with $\mathrm{SiC}$ emery papers of 1200 grits by hand, and then carefully cleaned with air flow generated by a plastic syringe. The compressive strength of the as-fabricated scaffold was measured at a crosshead speed of $0.5 \mathrm{~mm} \mathrm{~min}^{-1}$ using a universal testing machine (Instron-1195, USA) in accordance with ASTM D695-91. Six repeat tests were performed for each scaffold and the results were expressed in the form of mean \pm standard deviation (SD).
Immersion testing in simulated body fluid

A simulated body fluid (SBF) solution was prepared according to the procedure described by Kokubo [25]. The ion concentrations of SBF were similar to those in human blood plasma, and the $\mathrm{pH}$ value was set at 7.35 [25]. The 7-day-set scaffolds were carefully cut into samples with a diameter of $6 \mathrm{~mm}$ and a height of $4 \mathrm{~mm}$. The samples were soaked in the $50 \mathrm{~mL} \mathrm{SBF}$ solution at $37.0{ }^{\circ} \mathrm{C}$ in a shaking water bath for 7 days [26]. Then, the disks were gently rinsed with deionized water to remove the retained SBF solution, followed by drying at room temperature. The samples were characterized by using an X-ray diffractometer (XRD; Geigerflex, Rigaku Co., Japan) with monochromated $\mathrm{CuK}_{\alpha}$ radiation and the $2 \theta$ range was from 10 to $80^{\circ}$ at a scanning speed of $10 \% \mathrm{~min}$, and a scanning electron microscope (SEM; JSM-6700F, JEOL, Tokyo, Japan) equipped with an energy dispersive X-ray spectrometer (EDX, INCA Energy, Oxford Instruments, UK).

Statistical methods

The data obtained from the investigations were analyzed using the Student's $t$-test method and expressed in the form of mean \pm standard deviation (SD). A $p$-value $<0.05$ was considered statistically significant.

\section{Results}

Porous structure

Figure 1 shows the morphologies of the as-fabricated scaffolds after aging in the $37{ }^{\circ} \mathrm{C} / 100 \% \mathrm{RH}$ water bath for 7 days. No macro-sized pores on the sample Scaffold-10H or on its cross-section could be observed (Fig. 1a, b). However, as the concentration of $\mathrm{H}_{2} \mathrm{O}_{2}$ increased to $20 \%$, the Scaffold-20H displayed an obvious macroporous structure, and the pores were round and quite homogeneous (Fig. 1c, d). In addition, most of the pores inside the Scaffold-20H sample appeared to be isolated from each other, meaning a low level of interconnectivity (Fig. 1d). As the concentration of $\mathrm{H}_{2} \mathrm{O}_{2}$ as the foaming agent further increased to $30 \%$, the sample Scaffold $-30 \mathrm{H}$ contained pores of larger sizes and the pores became less regular in shape (Fig. 1e, f), as compared with those of Scaffold-20H. Moreover, the pores in Scaffold-30H had an increased level of interconnectivity as observed by SEM (Fig. 2). Scaffold$30 \mathrm{H}$ appeared to be most interesting and was subjected to further microstructural characterization.

The samples Scaffold-20H and Scaffold-30H were fractured to reveal possible preferential orientation of the pores on the longitudinal and transverse sections (Fig. 2). 
Fig. 1 Optical micrographs showing the porous structures of the $\mathrm{Ca}_{3} \mathrm{SiO}_{5}$ scaffolds prepared with the $\mathrm{H}_{2} \mathrm{O}_{2}$ solutions of various concentrations, $\mathbf{a}$ and $\mathbf{b}$ $10 \% \mathrm{H}_{2} \mathrm{O}_{2} ;$ c and d $20 \% \mathrm{H}_{2} \mathrm{O}_{2}$ b and $\mathbf{f} 30 \% \mathrm{H}_{2} \mathrm{O}_{2}$. b, d, and $\mathbf{f}$ show the porous structures of the samples on the cross-section
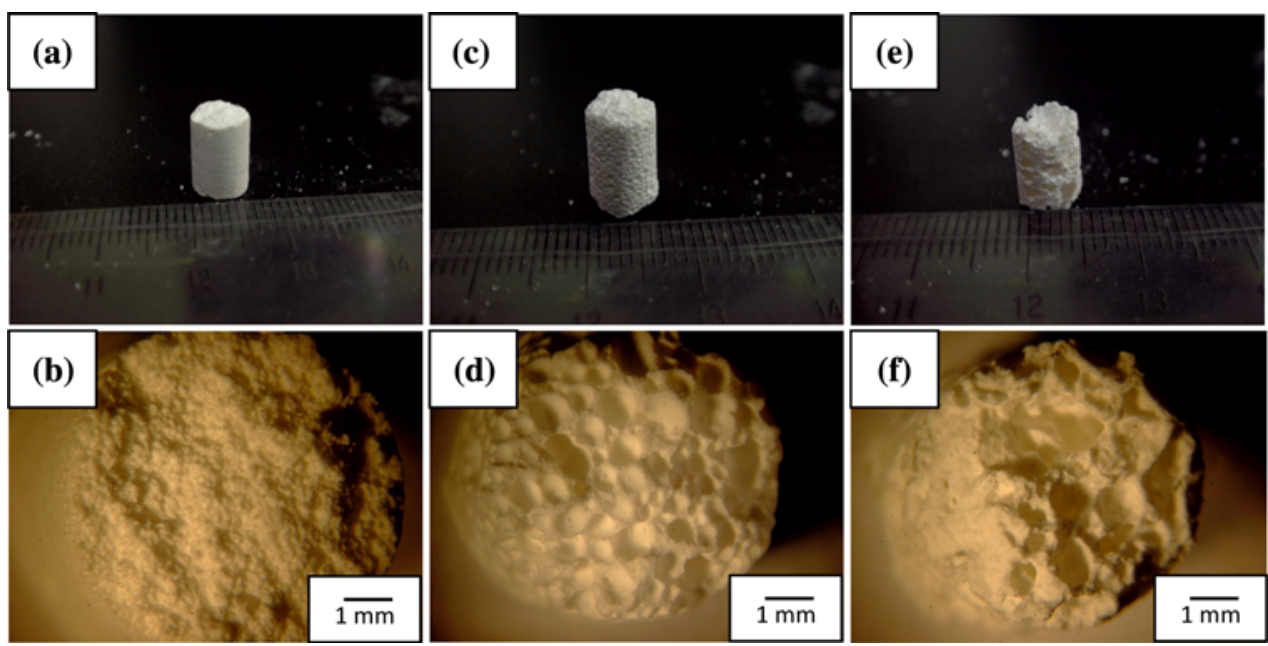
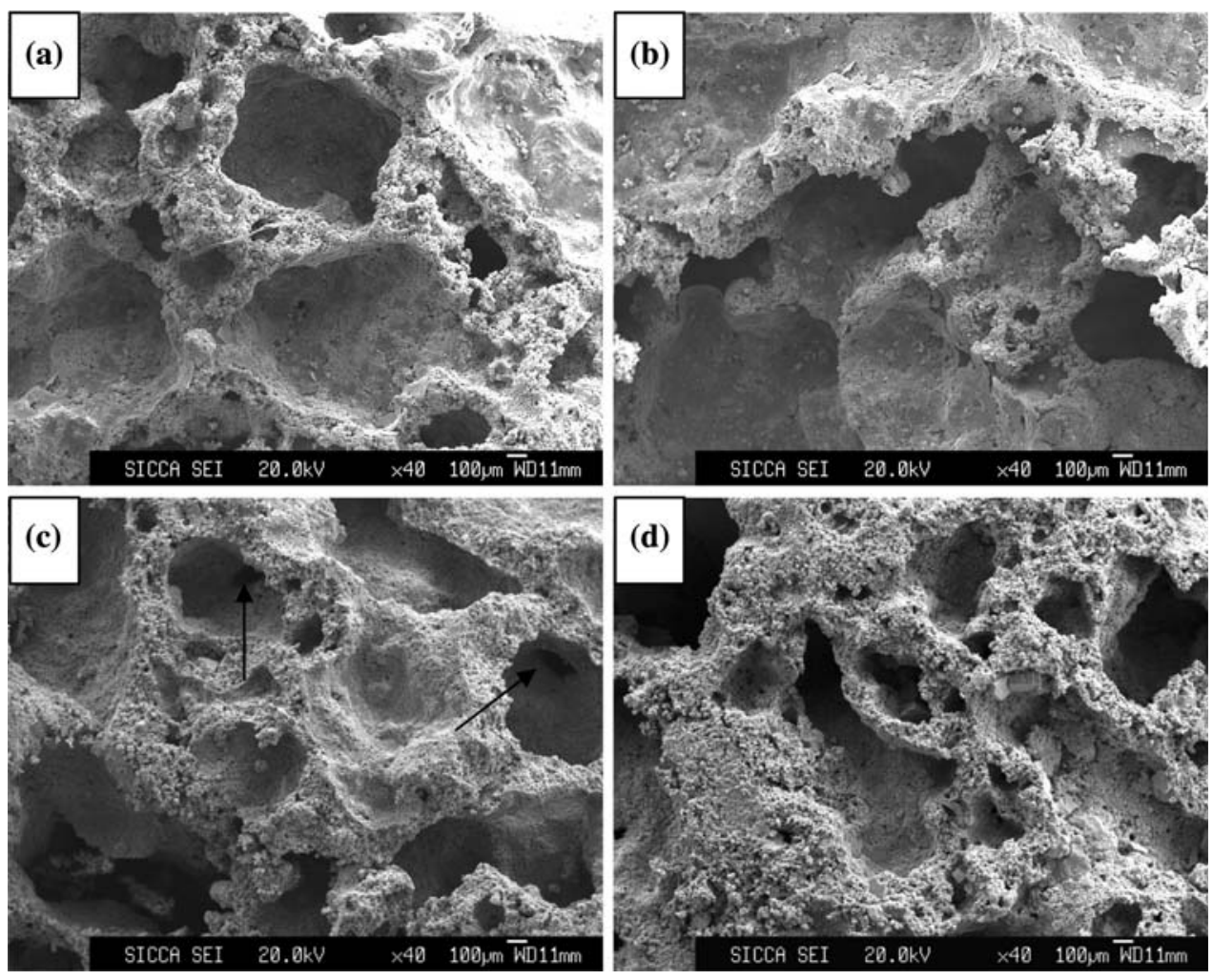
Scaffold-20H (a, b) and Scaffold-30H (c, d) aged for 7 days and then fractured to reveal possible preferential orientation of pores on the transverse $(\mathbf{a}, \mathbf{c})$ and longitudinal $(\mathbf{b}, \mathbf{d})$ sections. $(\mathbf{a}, \mathbf{b}, \mathbf{c}, \mathbf{d} \times 40)$

It was found that the porous structure of Scaffold-20H showed a lower level of interconnectivity than that of Scaffold-30H, which confirmed the results from the optical microscopy observation (Fig. 1). Networks of macropores were found in the Scaffold- $30 \mathrm{H}$ and these are shown in Fig. 2c, d. Macropores with sizes of several $100 \mu \mathrm{m}$ were homogeneously distributed on both the transverse (Fig. 2c) and longitudinal sections (Fig. 2d). A comparison between Fig. 2c, d shows insignificant differences in the sizes and shape of the pores as well as interconnectivity between the longitudinal section and the transverse section.

Figure 3 shows the microporous structures of a strut (a and b) and its inner wall (c and d), which is the frame that resists longitudinal compression and located between the individual pores. Both the cross-section and inner wall of the strut contained micropores swith sizes around $10 \mu \mathrm{m}$ (Fig. 3a, c). SEM micrographs at a higher magnification showed that the microporous surface was actually composed of aggregates of tiny particles (Fig. 3b, d), 
Fig. 3 SEM micrographs showing the porous structure of a single strut of Scaffold- $30 \mathrm{H}$ on the cross-section (a and b) and on its inner wall (c and d) $(\mathbf{a}, \mathbf{b} \times 500 ; \mathbf{c}, \mathbf{d} \times 5000)$
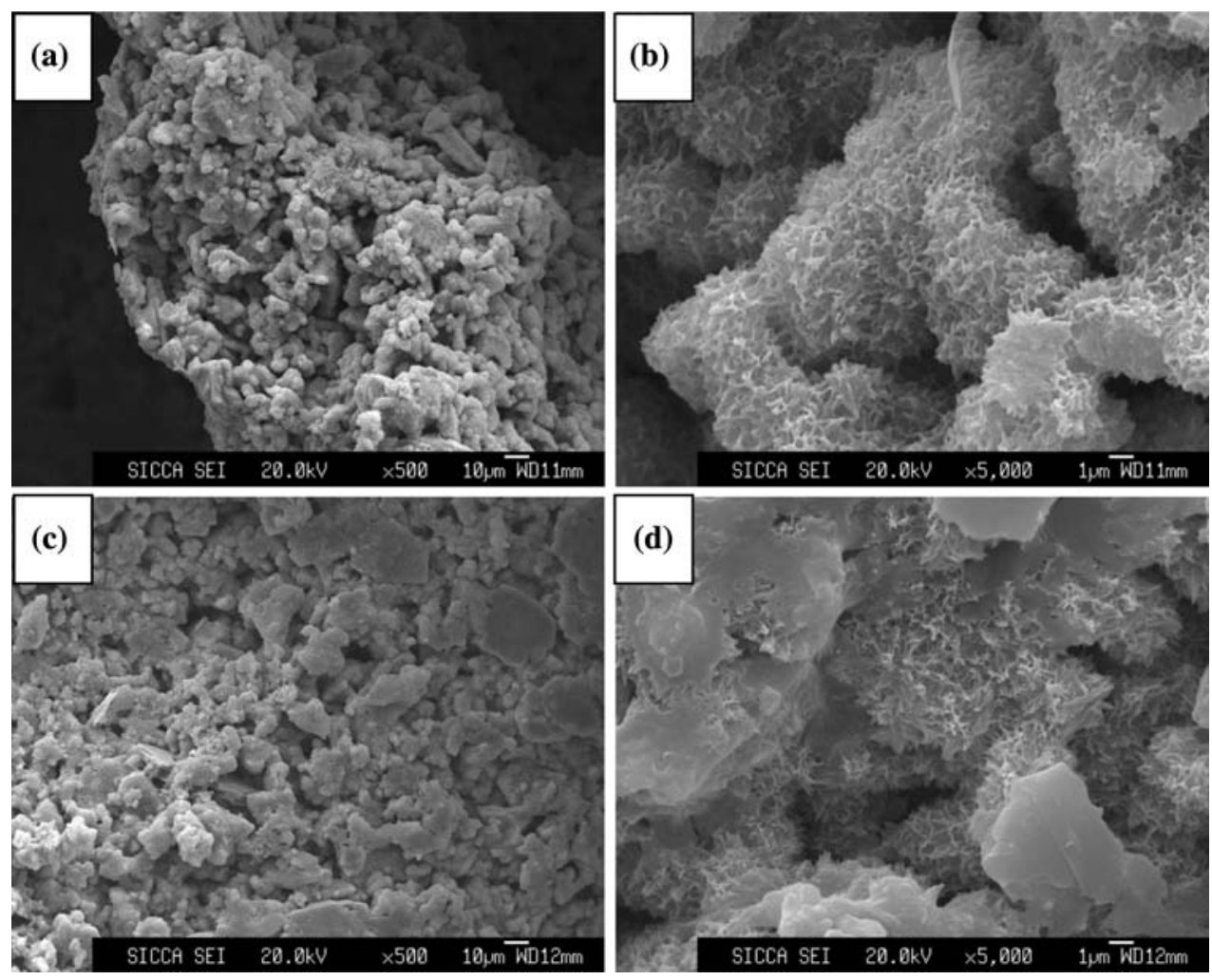

being characteristic of hydrated tricalcium silicate cement [21].

Mechanical properties and porosity

The variations of compressive strength and porosity with the concentration of $\mathrm{H}_{2} \mathrm{O}_{2}$ solution are presented in Table 1 . The Cement-D specimens had a mean compressive strength of $12.53 \mathrm{MPa}$ and a porosity level of $35.3 \%$. Note that no obvious macropores were observed in the hydrated paste Cement-D due to the absence of the foaming agent. An addition of the foaming agent $\left(\mathrm{H}_{2} \mathrm{O}_{2}\right)$ significantly increased the overall porosity of the paste, which led to a decreased mechanical strength. As shown in Table 1, increasing the concentration of the foaming agent solution resulted in a significant increase in the total porosity and consequently a decreased compressive strength of the scaffold.
Phases formed during aging

Figure 4 shows the XRD patterns of the initial tricalcium silicate powder (Fig. 4a), hydrated Cement-D, and Scaffold-30H after aging for 7 days. Both the Scaffold-30H and hydrated Cement-D contained calcium carbonate, calcium hydroxide $\left[\mathrm{Ca}(\mathrm{OH})_{2}\right]$, and calcium silicate hydrate $(\mathrm{C}-\mathrm{S}-\mathrm{H})$, with the latter two components being the main hydration products of tricalcium silicate. In combination with the results of SEM investigation, the XRD patterns confirmed that the hydration reaction took place during the aging process. In addition, the intensities of the XRD peaks associated with $\mathrm{Ca}(\mathrm{OH})_{2}$ and $\mathrm{C}-\mathrm{S}-\mathrm{H}$ in the Scaffold- $30 \mathrm{H}$ sample were much higher than those in the Cement-D sample, indicating that the foaming process might have an accelerating effect on the hydration of tricalcium silicate.

Table 1 Compressive strengths and porosity of the as-fabricated samples after aging for 7 days

\begin{tabular}{lllll}
\hline & Cement-D & Scaffold-10H & Scaffold-20H & Scaffold-30H \\
\hline Compressive strength (MPa) & $12.53 \pm 1.31$ & $3.66 \pm 0.54^{*}$ & $1.28 \pm 0.17^{*}$ & $0.28 \pm 0.03^{*}$ \\
$P_{\text {total }}(\%)$ & $35.3 \pm 2.8$ & $50.9 \pm 3.2^{*}$ & $67.1 \pm 6.8^{*}$ & $83.1 \pm 7.7^{*}$ \\
$P_{\text {macro }}(\%)$ & - & 15.6 & 31.8 & 47.8 \\
\hline
\end{tabular}

Asterisk $(*)$ indicates statistical significant difference $(p<0.05)$ between the samples in different groups 
Phases formed after immersion in SBF

The bioactivity of a scaffold depends on the phases formed on its surface when in contact with human extracellular

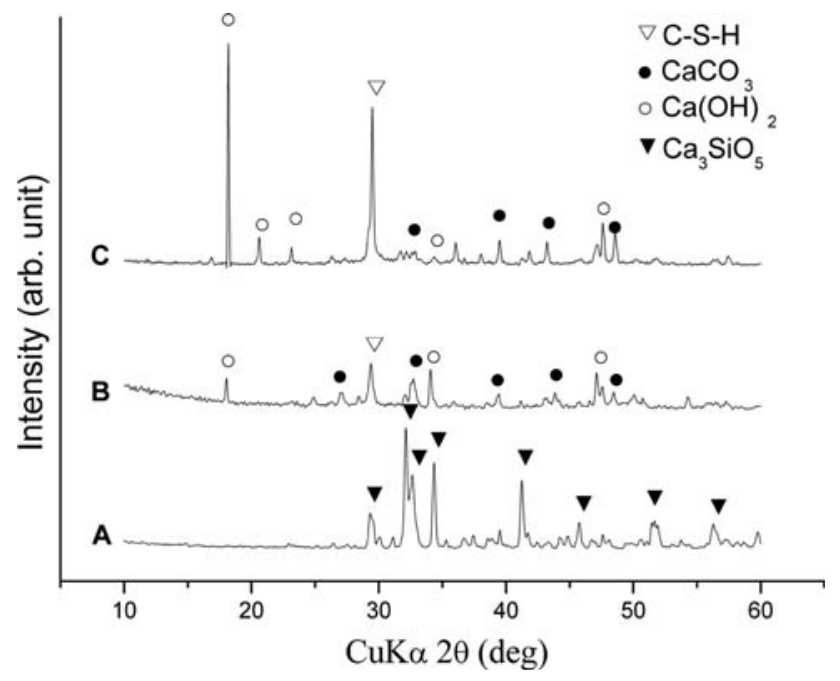

Fig. 4 XRD patterns of the samples: a tricalcium silicate powder; b Cement-D, and c Scaffold-30H after aging for 7 days

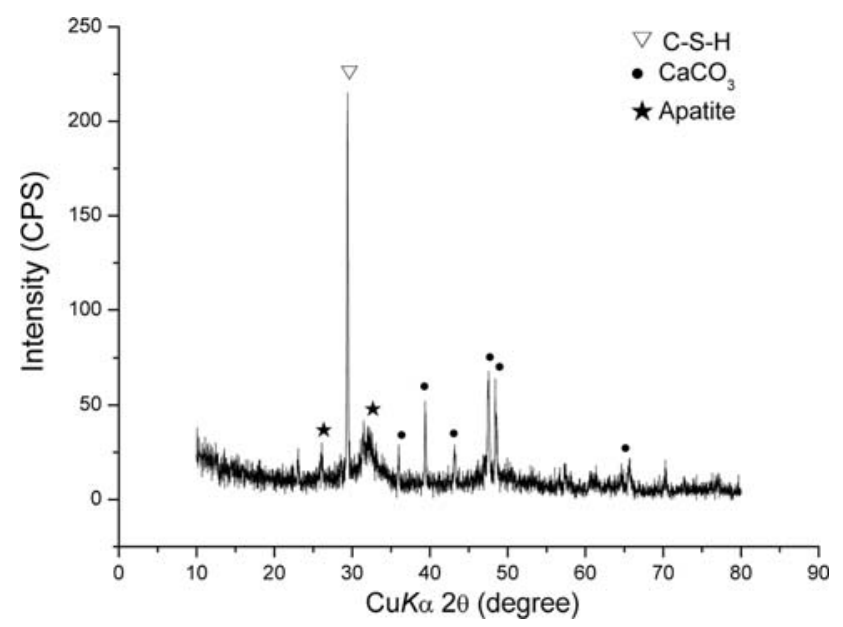

Fig. 5 XRD patterns of the Scaffold-30H samples after soaking in SBF for 7 days fluid. Scaffold-30H was selected to be soaked in SBF, and XRD and SEM patterns of the samples after soaking in SBF are shown in Figs. 5 and 6, respectively. It was clear to see from Fig. 5 that characteristic peaks of $\mathrm{Ca}(\mathrm{OH})_{2}$ disappeared and characteristic peaks for apatite at $2 \theta=26.04^{\circ}$ and $32.72^{\circ}$ appeared after 7 days of soaking $[21,25,27]$. SEM micrographs of the scaffold after soaking in SBF for 7 days (Fig. 6) showed that the scaffold remained to be macroporous after a soaking period of 7 days (Fig. 6a), and newly formed small granules became visible on the surfaces of struts (Fig. 6b). Examination at a higher magnification (Fig. 6b) showed that the surface of the granules contained crystals with a lath-like morphology of typical bone-like apatite, being similar to those formed on the surface of bioactive glass [26] and silicate bioceramics [12] after soaking in SBF. The sizes of the crystals were about $80 \mathrm{~nm}$ in diameter (Fig. 6b). EDX analysis of the lath-like crystals (Fig. 7) indicated a Ca: P molar ratio of 1.63 , being quite close to the stoichiometric ratio of hydroxyapatite (1.67). EDX analysis in combination with XRD analysis and SEM observation confirmed the formation of a bone-like apatite layer on the struts of the scaffold during soaking in SBF.

\section{Discussion}

$\mathrm{H}_{2} \mathrm{O}_{2}$ is often used as a foaming agent to prepare porous scaffolds. The method has been reported to be efficient for the fabrication of macroporous scaffolds with bioactive silicate-containing materials as the matrix [28]. Such a foaming method is normally followed by a high-temperature sintering step, which is necessary for the integrity of the as-fabricated scaffold. However, the fabrication method developed in this research to fabricate silicate-containing bioactive scaffolds involves the combination of foaming and hydration of tricalcium silicate at low temperatures. The cementitious hydration of the paste leads to the solidification of the scaffold, which helps it gain required integrity without sintering at high temperature. The porosity of the
Fig. 6 SEM micrographs showing the surface microstructure of the Scaffold$30 \mathrm{H}$ sample after soaking in SBF for 7 days: a at a low magnification $(30 \times)$ and $\mathbf{b}$ at $\mathbf{a}$ high magnification $(30,000 \times)$, and the small SEM image in the top right corner of a indicated the focused area of the surface for the subsequent EDX analysis
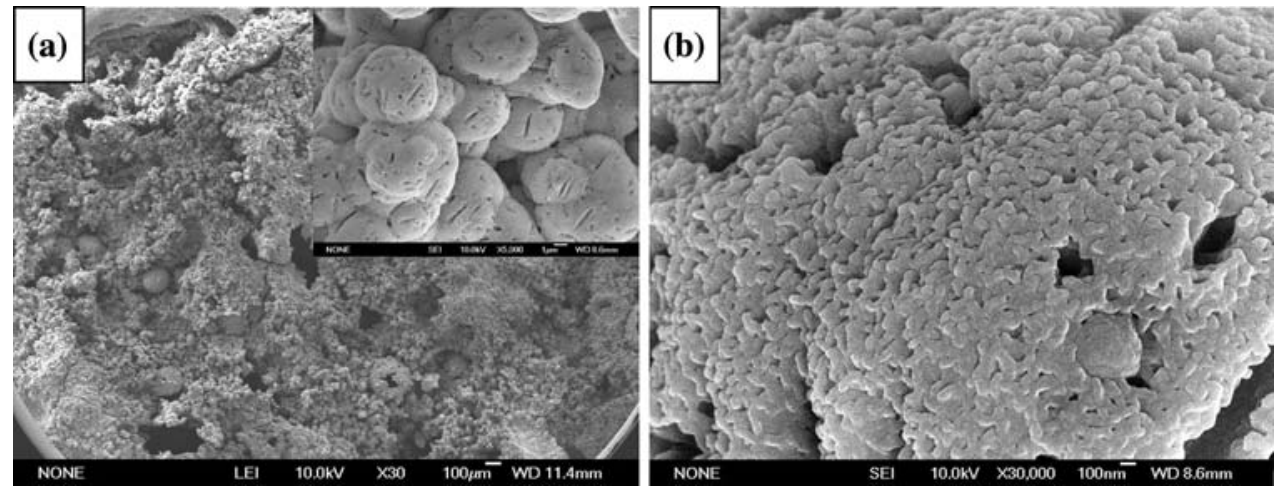


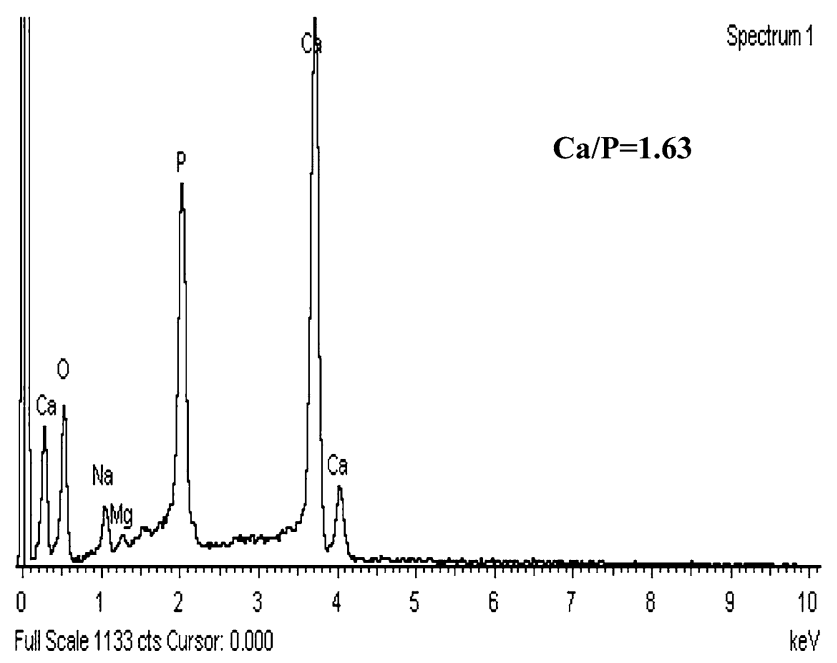

Fig. 7 EDX analysis of the surface of the Scaffold-30H sample after soaking in $\mathrm{SBF}$ for 7 days $(\mathrm{Ca} / \mathrm{P}=1.63)$

scaffold is composed of foaming-induced macroporosity and intrinsic microporosity formed during the hydration of tricalcium silicate. The overall process involves the following reactions:

$$
\begin{aligned}
& \mathrm{H}_{2} \mathrm{O}_{2} \rightarrow \mathrm{H}_{2} \mathrm{O}+\mathrm{O}_{2} \uparrow \\
& \mathrm{C}_{3} \mathrm{~S}+\mathrm{H}_{2} \mathrm{O} \rightarrow \mathrm{C}-\mathrm{S}-\mathrm{H}+\mathrm{Ca}(\mathrm{OH})_{2}
\end{aligned}
$$

It appears that the porosity level of the scaffold depends on the $\mathrm{H}_{2} \mathrm{O}_{2}$ concentration and its integrity can be achieved by the hydration and setting of tricalcium silicate cement. As the concentration of the foaming agent increases, more gas release from the decomposition of $\mathrm{H}_{2} \mathrm{O}_{2}$ occurs, leaving the scaffold with a more porous structure and pores of larger sizes. In addition, the increased amount of gas produced by the decomposition of $\mathrm{H}_{2} \mathrm{O}_{2}$ results in an increased possibility for gas bubbles to contact each other. Therefore, not only macroporosity but also interconnectivity increases with increasing concentration of $\mathrm{H}_{2} \mathrm{O}_{2}$. The use of $\mathrm{H}_{2} \mathrm{O}_{2}$ as a foaming agent is thus proven to be an efficient method to fabricate porous silicate-containing scaffolds.

Basically, there are two main advantages of the present method that use $\mathrm{H}_{2} \mathrm{O}_{2}$ as a foaming agent in connection with the subsequent hydration of tricalcium silicate. Firstly, it allows for the introduction of a high level of macroporosity in the material without the addition of other substances that may be cytotoxic. The scaffold is mainly composed of calcium silicate hydrate and calcium hydroxide that are both the final hydration products of tricalcium silicate and have been proven to be non-cytotoxic in cell culture $[21,29]$. Secondly, a higher hydration rate of tricalcium silicate may lead to enhanced bonding between matrix particles by improving the agglomeration and the subsequent solidification of $\mathrm{C}-\mathrm{S}-\mathrm{H}$ gel networks. It is assumed that with the formation of macroporous structure by the decomposition of $\mathrm{H}_{2} \mathrm{O}_{2}$ as porogen, the reactive surface for the hydration would be larger in the scaffold than in the specimen without porogen during the aging process in humidity, and such an increase in reactive surface has been figured out in a previous research on the fabrication of porous PLGA microspheres with $\mathrm{H}_{2} \mathrm{O}_{2}$ as porogen [30]. Therefore, an accelerated hydration and resultant higher content of hydration product within the scaffold were observed from the results of XRD analysis (Fig. 4). The compressive strength of the scaffold Scaffold$30 \mathrm{H}$ (about $0.3 \mathrm{MPa}$, see Table 1) falls in the range of the strengths of spongy bone (not the strut) (0.2-4 MPa [31]) and is close to the lower bound. Other studies on scaffolds for bone tissue engineering indicate it may not be necessary to fabricate a porous scaffold with a mechanical strength equal to the bone, because cultured cells on the porous scaffold and new tissue formation in vitro will create a biocomposite, thereby increasing the time-dependent strength of the scaffold significantly [13, 32].

An important characteristic of a bioactive silicate-containing material is its ability to bond with living bone through the formation of a HAp interface layer on its surface both in vitro and in vivo $[4,6]$. The present study showed that porous $\mathrm{C}_{3} \mathrm{~S}$ scaffolds induced the precipitation of a HAp layer on their surfaces in SBF during a relatively short soaking period of 7 days, which suggests a high degree of bioactivity of the macroporous scaffolds attributed to the excellent bioactivity of tricalcium silicate cement as the substrate. In addition, it has been reported that this bone-like apatite layer can provide a suitable substrate for osteoblast-like cell proliferation and function, which allows a strong bonding of the material to the surrounding bone tissue [33]. Furthermore, the biocompatibility of bioactive sol-gel glasses with a HAp layer is greatly enhanced as compared to those without a HAp layer [34]. Therefore, the bioactive $\mathrm{C}_{3} \mathrm{~S}$ scaffolds fabricated in the present work are expected to interact positively with cells by developing a remineralization layer. In addition, the surface modification as occurred during soaking in SBF will enhance material-cell interactions.

\section{Conclusions}

In this study, macroporous silicate-containing scaffolds were successfully fabricated through low-temperature foaming and hydration of tricalcium silicate cement. The scaffolds contained both interconnected macropores and intrinsic micropores. These scaffolds were mainly composed of biocompatible calcium silicate hydrate. Their bioactivity was assured as a result of the formation of a HAp layer on the surface of scaffolds during immersion in 
SBF. The tricalcium silicate-derived scaffolds fabricated using the simple two-step method developed in the present research look promising for bone tissue engineering applications.

Acknowledgements The research was supported by the National Basic Science Research Program of China (973 Program) (Grant No.: 2005CB522704), Science and Technology Commission of Shanghai Municipality (Grant No.: 08JC1420800) and the Natural Science Foundation of China (Grant 30730034).

\section{References}

1. Hutmacher DW (2000) Biomaterials 21:2529

2. Hench LL (2006) J Mater Sci Mater Med 17:967

3. Oonishi H, Kutrshitani S, Yasukawa E, Iwaki H, Hench LL, Wilson J, Tsuji E, Sugihara T (1997) Clin Orthop Relat Res 334:316

4. Hench LL, Paschall HA (1973) J Biomed Mater Res Symp 4:25

5. Lin KL, Zhai WY, Ni SY, Chang J, Zeng Y, Qian WJ (2005) Ceram Int 31:323

6. Gatti AM, Valdre G, Andersson OH (1994) Biomaterials 15:208

7. Hench LL (1997) Curr Opin Solid State Mater Sci 2:604

8. Kaufmann EABE, Ducheyne P, Shapiro IM (2004) Tissue Eng 6:19

9. Binner JGP, Reichert J (1996) J Mater Sci 31:5717. doi: 10.1007/BF01160820

10. Lin KL, Chang J, Zeng Y, Qian WJ (2004) Mater Lett 58:2109

11. Jones JR, Hench LL (2004) J Biomed Mater Res B Appl Biomater 68B:36

12. Ni SY, Chang J, Chou L (2006) J Biomed Mater Res A 76A:196

13. Chen ZQZ, Thompson ID, Boccaccini AR (2006) Biomaterials 27:2414

14. Bretcanu O, Samaille C, Boccaccini AR (2008) J Mater Sci 43:4127. doi:10.1007/s10853-008-2536-y
15. Li P, Zhang F, Kokubo T (1992) J Mater Sci Mater Med 3:452

16. Clupper DC, Hench LL (2003) J Non-Cryst Solids 318:43

17. FitzGerald SA, Thomas JJ, Neumann DA, Livingston RA (2002) Cem Concr Res 32:409

18. Bensted J, Barnes P (2002) Structure and performance of cements. Spon press, New York

19. Chen JJ, Thomas JJ, Taylor HFW, Jennings HM (2004) Cem Concr Res 34:1499

20. Zhao WY, Chang J (2004) Mater Lett 58:2350

21. Zhao WY, Wang JY, Zhai WY, Wang Z, Chang J (2005) Biomaterials $26: 6113$

22. Almirall A, Larrecq G, Delgado JA, Martinez S, Planell JA, Ginebra MP (2004) Biomaterials 25:3671

23. Wang X, Ruan J, Chen Q (2009) Mater Res Bull 44:1275

24. ASTM C 20-00 (2005) Standard test methods for apparent porosity, water absorption, apparent specific gravity, and bulk density of burned refractory brick and shapes by boiling water. ASTM International, West Conshohocken, USA. doi:10.1520/ C0020-00R05

25. Kokubo T (1990) J Non-Cryst Solids 120:138

26. Jones JR, Ehrenfried LM, Hench LL (2006) Biomaterials 27:964

27. Li XK, Chang J (2006) J Mater Sci 41:4944. doi:10.1007/s10853006-0305-3

28. Yuan HP, Bruijn JD, Zhang XD, Blitterswijk CA, Groot K (2001) J Biomed Mater Res B Appl Biomater 58:270

29. Leonardo RT, Consolaro A, Carlos IZ, Leonardo MR (2000) J Endod 26:328

30. Bae SE, Son JS, Park K, Han DK (2009) J Control Release 133:37

31. Callcut S, Knowles JC (2002) J Mater Sci Mater Med 13:485

32. Tamai N, Myoui A, Tomita T, Nakase T, Tanaka J, Ochi T (2002) J Biomed Mater Res 59:110

33. Loty C, Sautier JM, Boulekbache H, Kokubo T, Kim HM, Forest N (2000) J Biomed Mater Res 49:423

34. Olmo N, Mratı'n AI, Salinas AJ, Turnay J, Vallet-Reg M, AntoniaLizarbe M (2003) Biomaterials 24:3383 